\title{
Prevalence of asthma in Melbourne schoolchildren: changes over 26 years
}

\author{
Colin F Robertson, Elizabeth Heycock, Janet Bishop, Terry Nolan, Anthony Olinsky, \\ Peter D Phelan
}

\begin{abstract}
Objectives-To determine the prevalence of asthma in the past 12 months in Melbourne schoolchildren aged 7,12 , and 15 years and to compare the prevalence of a history of asthma with that of 26 years ago.

Design-A questionnaire on respiratory symptoms was distributed to children for completion by parents and return to the school. Subjects were selected by a stratified cluster design.

Setting-Government and non-government schools in the greater Melbourne area, Australia.

Subjects-10981 children. Parents completed questionnaires for 3324 children aged 7, 2899 aged 12 , and 2968 aged 15 . The overall response rate was $90 \%$.
\end{abstract}

Main outcome measures-History of wheeze or asthma in the past 12 months and in lifetime.

Results - The prevalences of wheeze in the past 12 months were $23 \cdot 1 \%, 21 \cdot 7 \%$, and $18 \cdot 6 \%$ for 7,12 , and 15 year olds respectively. A history of wheeze was more common in boys than in girls at age $7(443 / 1711$ $v 324 / 1614)$ and $12(418 / 1767 . v 322 / 1718)$ but not at age 15. Overall, $78 \%$ (1548) of those reporting wheeze also reported a history of asthma and $83 \%$ (1611) had used a bronchodilator. The prevalence of a history of asthma among 7 year olds was $46 \%$ compared with $19 \cdot 1 \%$ in the 1964 survey, an increase of $141 \%$.

Conclusions - The current prevalence of asthma in Melbourne schoolchildren is high and has risen substantially over the past 26 years.

Department of Thoracic Medicine, Royal Children's Hospital, Melbourne, Australia 3054

Colin F Robertson, FRACP, respiratory physician

Elizabeth Heycock, MRCP research fellow

Anthony Olinsky, FRACP, director

Clinical Epidemiology and Biostatistics Unit, University of Melbourne, Melbourne, Australia Janet Bishop, MSC, epidemiologist

Terry Nolan, PHD, director

Department of Paediatrics, University of Melbourne Royal Children's Hospital Melbourne, Australia 3054 Peter D Phelan, MD, chairman

Correspondence to:

Dr Robertson.

BMF 1991;302:1116-8

\section{Introduction}

The prevalence of asthma has been reported to be increasing in the United Kingdom and New Zealand. ${ }^{12}$ Similar increases have been reported in hospital admission rates for asthma in the United Kingdom, New Zealand, United States, and Australia, ${ }^{3-6}$ but we do not know whether this increase is real or due to changes in medical practice or diagnostic labelling. Recently, Burney et al suggested that the increase in asthma morbidity is real. ${ }^{7}$ In Australia, the hospital admission rate for paediatric asthma has increased significantly, to 4.13 per 1000 population in 1986. Australia has the second highest reported mortality from asthma in the world, ${ }^{8}$ and over the past 10 years mortality in the $0-19$ age group has increased by $50 \%$ (Australian Bureau of Statistics). Reasons proposed for this increase include a change in diagnostic fashion, an increase in the severity of asthma, and a true increase in prevalence.

In 1964 a survey of 7 year old Melbourne schoolchildren found a prevalence of a history of symptoms suggestive of asthma of $19 \cdot 1 \%$, which was far higher than prevalences found in other published studies at the time. ${ }^{9}$ We studied a similar population of children to determine if the prevalence of asthma had changed.
Subjects and methods

Three age groups were selected for study: 7 year olds (school year 2), 12 year olds (school year 7 ), and 15 year olds (school year 10). The 7 year olds were selected for direct comparison with the 1964 study $^{9}$; the 12 year olds because by this age respiratory infection seems to be a minor component of asthma and the perception of the patient and parents about the nature of wheezing and its requirement for treatment may change; and 15 year olds because after this age many children leave school. Retention rates for year 10 in Victoria are $99 \cdot 3 \%$. To provide $95 \%$ certainty of being within $1 \%$ of the true prevalence of current asthma, assuming it to be $10 \%$, approximately 3225 subjects in each group were studied.

We used a two stage sample design. Schools were randomly sampled for study from metropolitan Melbourne and adjacent areas within one hour's drive from the centre of Melbourne. We invited all children in the relevant grade of the selected school to participate; government, Catholic, and independent schools were included. For administrative purposes schools with 30 or fewer second year students were excluded. To prevent an overrepresentation of the remaining small schools all schools with 31-50 second year students were paired with the nearest school on the sampling frame to form a "pseudoschool." The sampling procedure therefore selected a mixture of pseudoschools (62-100 students) and regular schools ( $\geqslant 51$ students).

This two stage design may result in clustering of similar students within schools. As clustering can cause an underestimation of standard error if simple random sample methods are used we adjusted the sample size used for calculating standard error using the sample estimate of the intraclass correlation coefficient. $^{10}$

We issued a three page questionnaire on respiratory symptoms to schools for distribution to parents (appendix). The questionnaire included questions used in similar surveys ${ }^{11-13}$ and three questions identical to those used in $1964 .{ }^{9}$ Translations into six common languages in the community were available in identical format. Questionnaires were issued on a second occasion if the first was not returned.

We used the statistical package SPSS X to categorise and analyse the data. $\chi^{2}$ Analyses of contingency tables and $\chi^{2}$ test for trend were used to assess the differences in the prevalence rates.

\section{Results}

Seventy one of 963 primary schools and 27 of 380 secondary schools in the area were selected for study. We issued 10198 questionnaires and 9192 were returned completed, an overall response rate of $90 \%$. Table I gives parents' responses to the questions.

Reported wheeze was significantly more common in the 7 year olds than in the 15 year olds, as were sleep disturbance due to wheeze, night cough, and use of bronchodilators $(p<0 \cdot 001)$. Exercise induced wheeze 


\begin{tabular}{|c|c|c|c|}
\hline \multirow[b]{2}{*}{ Variable } & \multicolumn{3}{|c|}{ Age of children (years) } \\
\hline & 7 & 12 & 15 \\
\hline Mean (SD) age (years) & $7 \cdot 3(0.63)$ & $12 \cdot 3(0.42)$ & $15 \cdot 3(0 \cdot 49)$ \\
\hline No of questionnaires issued & 3473 & 3274 & 3451 \\
\hline No $(\%)$ responding & $3325(96)$ & $2899(89)$ & $2968(86)$ \\
\hline Ever had wheeze & $1362(41 \cdot 0 ; 38 \cdot 8$ to $43 \cdot 2)$ & $1059(36 \cdot 5 ; 32 \cdot 6$ to $40 \cdot 4)$ & $1054(35.5 ; 32.3 \text { to } 38 \cdot 7)^{\star}$ \\
\hline Ever had asthma & $802(24 \cdot 1 ; 22 \cdot 1$ to $26 \cdot 1)$ & $673(23 \cdot 2 ; 20 \cdot 3$ to $26 \cdot 0)$ & $653(22 \cdot 0 ; 19.9$ to $24 \cdot 1)$ \\
\hline \multicolumn{4}{|l|}{ Symptoms in past 12 months: } \\
\hline Wheeze & $767(23 \cdot 1 ; 21 \cdot 7$ to $24 \cdot 5)$ & $628(21 \cdot 7 ; 19 \cdot 4$ to $22 \cdot 4)$ & $553(18 \cdot 6 ; 17 \cdot 0 \text { to } 19 \cdot 8)^{\star}$ \\
\hline Sleep disturbance & $482(14 \cdot 5 ; 13 \cdot 2$ to $15 \cdot 8)$ & $317(10 \cdot 9 ; 9 \cdot 4$ to $12 \cdot 4)$ & $260(8.8 ; 7.9$ to 9.7$)$ \\
\hline Severe episode & $119(3.6 ; 2.9$ to 4.3$)$ & $104(3.6 ; 2.9$ to 4.3$)$ & $101(3.4 ; 2.8$ to 3.9$)$ \\
\hline Exercise induced wheeze & $500(15.0 ; 13.7$ to 16.4$)$ & $592(20 \cdot 4 ; 17 \cdot 5$ to $23 \cdot 3)$ & $686(23 \cdot 1 ; 20 \cdot 7 \text { to } 25 \cdot 5)^{\star}$ \\
\hline Night cough & $934(28 \cdot 1 ; 26 \cdot 5$ to $29 \cdot 7)$ & $560(19 \cdot 3 ; 17 \cdot 6$ to $21 \cdot 0)$ & $478(16 \cdot 1 ; 14.7 \text { to } 17 \cdot 6)^{\star}$ \\
\hline Morning mucous & $499(15 \cdot 0 ; 13 \cdot 8$ to $16 \cdot 2)$ & $462(15 \cdot 9 ; 14 \cdot 3$ to $17 \cdot 5)$ & $620(20 \cdot 9 ; 19 \cdot 4 \text { to } 22 \cdot 4)^{\star}$ \\
\hline Morning tightness & $322(9 \cdot 7 ; 8.7$ to $10 \cdot 7)$ & $325(11 \cdot 2 ; 9 \cdot 8$ to $12 \cdot 6)$ & $389(13 \cdot 1 ; 11.9 \text { to } 14 \cdot 2)^{\star}$ \\
\hline Wheeze with allergens & $203(6 \cdot 1 ; 5 \cdot 3$ to $6 \cdot 9)$ & $261(9 \cdot 0 ; 7 \cdot 8$ to $10 \cdot 2)$ & $348(11 \cdot 7 ; 10 \cdot 3 \text { to } 13 \cdot 1)^{\star}$ \\
\hline Used bronchodilators in the past 12 months & $918(27 \cdot 6 ; 25 \cdot 8$ to $29 \cdot 4)$ & $629(21 \cdot 7 ; 19 \cdot 3$ to $24 \cdot 1)$ & $575(19 \cdot 4 ; 17 \cdot 7 \text { to } 21 \cdot 2)^{\star}$ \\
\hline
\end{tabular}

${ }^{\star} \mathrm{p}<0.001$ for $\chi^{\prime}$ test for trend in proportions.

and wheeze on exposure to allergens were reported more commonly in the 15 year olds $(p<0 \cdot 001)$. In 7 year olds a history of wheeze in the past 12 months was more common in boys than in girls $(443 / 1711,25.9 \%$ boys $v 324 / 1614,20 \cdot 1 \%$ girls; $\mathrm{p}<0 \cdot 001)$. This gender difference was slightly less at age $12(418 / 1767 ; 23 \cdot 7 \% v$ $209 / 1132,18.5 \% ; p<0.01)$ and not seen at age 15 $(322 / 1718,18 \cdot 7 \%$ v $231 / 1250,18 \cdot 5 \%)$. At age 7 severe episodes of wheezing were reported more commonly in boys than in girls $(74,4.3 \% v 45,2 \cdot 8 \% ; \mathrm{p}<0.01)$ as was exercise induced wheeze $(297,17 \cdot 4 \%$ v 203, $12.6 \% ; \mathrm{p}<0 \cdot 001)$. These differences were not observed at other ages.

Of the 1984 children reported to have had wheeze in the past 12 months, 714 had had four or more attacks (table II); $599(78 \%)$ children aged 7, $494(79 \%)$ aged 12 , and $426(77 \%)$ aged 15 were also reported to have a history of asthma. Among children who had had four of more attacks of wheeze in the past 12 months, asthma was reported in $244(92 \%)$ aged 7, $226(92 \%)$ aged 12 , and $182(91 \%)$ aged 15 . A total of $1611(83 \%)$ children who had had wheeze in the past 12 months had used a bronchodilator, with the proportion increasing with increasing frequency of wheeze (table II). Among those reported to have ever had asthma and to have had four or more episodes of wheeze in the past 12 months, a bronchodilator was used in the past 12 months by 238/240 (99\%) aged 7, 221/228 (97\%) aged 12, and $178 / 180(99 \%)$ aged 15.

Some children who were reported as having had no wheeze in the past 12 months had had other respiratory symptoms suggestive of asthma (table III). Overall, 123 of the 409 children reported to have sounded wheezy after exercise in the past 12 months but not to have had a wheeze attack in the past 12 months used a bronchodilator. If this group was further defined to include only those reported ever to have had asthma $83 / 128(65 \%)$ were reported to have used a bronchodilator.

The prevalence of a history of asthma among 7 year

TABLE II - Frequency and other characteristics of wheeze in children reported to have wheezed in past 12 months. All values are numbers (percentages) of children

\begin{tabular}{|c|c|c|c|c|c|c|}
\hline \multirow[b]{2}{*}{ Symptoms in past 12 months } & \multicolumn{6}{|c|}{ Age of children (years) } \\
\hline & & $\begin{array}{c}7 \\
(\mathrm{n}=767)\end{array}$ & & $\begin{array}{c}12 \\
(n=628)\end{array}$ & & $\begin{array}{c}15 \\
(\mathrm{n}=553)\end{array}$ \\
\hline$<4$ episodes & & $496(65)$ & & $372(59)$ & & $342(62)^{\star}$ \\
\hline Used bronchodilators & $421(85)$ & & $271(73)$ & & $244(71)$ & \\
\hline 4-12 episodes & & $195(25)$ & & $171(27)$ & & $135(24)$ \\
\hline$<$ Used bronchodilators & $185(95)$ & & $160(94)$ & & $123(91)$ & \\
\hline $\begin{array}{l}>12 \text { episodes } \\
\text { Used bronchodilators }\end{array}$ & & $70(9)$ & & $76(12)$ & & $67(12)$ \\
\hline Used bronchodilators & $66(94)$ & & $75(99)$ & & $66(99)$ & \\
\hline Sleep disturbed by wheeze & & $468(61)$ & & $305(49)$ & & $251(45)^{\star}$ \\
\hline Severe episode & & $191(16)$ & & $102(16)$ & & $95(17)$ \\
\hline Exercise induced wheeze & & $438(57)$ & & $489(78)$ & & $442(80)^{\star}$ \\
\hline
\end{tabular}

${ }^{\star} \chi^{2}$ test for proportions of frequency of episodes, controlling for age $\mathrm{p}<0.001$. olds in the 1964 survey was determined by adding those whose parents responded positively to the questions Has your child ever had asthma? and Has your child ever had wheezing with bronchitis or cold? The prevalence in 1964 was $19 \cdot 1 \%$ compared with $46 \%$ $(1528 / 3325 ; 95 \%$ confidence interval $44 \cdot 3$ to $47 \cdot 7)$ in 1990 , representing an increase of $141 \%$. The prevalence of a history of asthma symptoms in the 12 and 15 year olds was $39 \cdot 7 \%(1151 / 2899)$ and $40 \cdot 3 \%$ (1196/2968) respectively.

TABLE III-Respiratory symptoms in children reported not to have wheezed in the past 12 month

\begin{tabular}{|c|c|c|c|}
\hline & \multicolumn{3}{|c|}{ Number (percentage) of children aged: } \\
\hline & $\begin{array}{c}7 \\
(n=2558)\end{array}$ & $\begin{array}{c}12 \\
(\mathrm{n}=2271)\end{array}$ & $\begin{array}{c}15 \\
(n=2415)\end{array}$ \\
\hline Exercise induced wheeze & $62(2 \cdot 4)$ & $103(4 \cdot 5)$ & $244(10 \cdot 1)$ \\
\hline Night cough & $371(14 \cdot 5)$ & $215(9 \cdot 5)$ & $222(9 \cdot 2)$ \\
\hline Morning tightness & $48(1.9)$ & $62(2 \cdot 7)$ & $124(5 \cdot 1)$ \\
\hline Use of bronchodilators & $241(9 \cdot 4)$ & $117(5 \cdot 2)$ & $136(5 \cdot 6)$ \\
\hline
\end{tabular}

\section{Discussion}

We found that the prevalence of a history of wheeze or asthma reported by parents was $46 \%$ among 7 year olds, $39 \cdot 7 \%$ among 12 year olds, and $40 \cdot 3 \%$ among 15 year olds. For 7 year olds this represents an increase of $141 \%$ over the past 26 years. Though some of this increase is probably real, part of it may be explained by a change in diagnostic labelling as a result of increased awareness of asthma in the medical and general communities. Similarly, the increase in the report of wheeze may well be due to an increase in awareness of the symptom of wheeze in the community; increased awareness could also result in some false positive reporting of wheeze.

Two recent studies have provided objective evidence of increased prevalence of asthma as assessed by exercise induced bronchoconstriction ${ }^{1}$ and increased morbidity due to asthma. ${ }^{7}$ All available objective measures of asthma morbidity, such as sales of drugs for asthma, ${ }^{14}$ increase in hospital admissions of people with asthma without reciprocal decrease in admissions due to other respiratory conditions, ${ }^{3-6}$ and mortality, ${ }^{8}$ have increased in recent years, but these may also be influenced by a change in diagnostic fashion. The objective evidence suggests that an appreciable component of the increase must be real. It is impossible, however, with current knowledge to accurately apportion reasons for the observed increase.

The prevalence of a history of wheeze or asthma we have found is far higher than in other studies. An earlier Australian study (1982-4) reported a prevalence of a history of respiratory symptoms of $34 \% .{ }^{15}$ Other recent international studies have reported prevalence 
in 7 year olds of $19 \cdot 4 \%$ in the United Kingdom ${ }^{16}$ and $29.4 \%$ in New Zealand.'

The prevalence of wheeze in the past 12 months in our study was higher in all age groups than prevalences in similar recent studies from the United Kingdom ${ }^{16}$ and New Zealand (table IV). ${ }^{1}$ The circa 1988 study of children in suburban Sydney suggested a prevalence of wheeze in the past 12 months of $17.7 \%$ in $8-12$ year old children. ${ }^{15}$ The increased prevalence of wheeze that we found among 7 year old boys is similar to that reported in the Southampton study $(14.3 \%$ in boys $v 9.5 \%$ in girls. "This difference diminished with increasing age, a trend also seen in the Southampton study.

TABLE IV-Percentage of children reported to have wheezed in past 12 months in different studies

\begin{tabular}{lccc}
\hline & \multicolumn{3}{c}{ Age of children (years) } \\
\cline { 2 - 4 } & 7 & 12 & 15 \\
\hline $\begin{array}{l}\text { Southampton, 1986' } \\
\begin{array}{l}\text { Dunedin, 1987 } \\
\text { Tyneside, 1987" }\end{array}\end{array}$ & $11 \cdot 9$ & $12 \cdot 3$ & \\
$\begin{array}{l}\text { Cardiff, 1988' } \\
\text { Melbourne, 1990 }\end{array}$ & $19 \cdot 5$ & & $8 \cdot 6$ \\
\hline
\end{tabular}

Though the prevalence of wheeze fell with increasing age, the prevalence of exercise induced wheeze, morning tightness, and wheeze on exposure to common allergens increased. The increase in exercise induced wheeze has not been reported previously. It may reflect a change in exercise patterns to endurance type exercise and the participation in organised sporting activities. The increased prevalence of wheeze on exposure to allergens may also reflect a change in the pattern of asthma. Whereas respiratory tract infections are the most common precipitating factors in young children these occur less often in teenagers, for whom the peak hospital admission rate occurs in spring.

Asthma was reported in roughly $79 \%$ of children who wheezed in the past 12 months, the same figure as quoted in the Southampton study ${ }^{16}$ and much higher than the $32 \%$ in Dunedin ${ }^{17}$ and $12 \%$ in the Tyneside study. ${ }^{18}$ The level of treatment with bronchodilators in our study was much higher at $84 \%$ overall and $96 \%$ (age 7) to $93 \%$ (age 15) in those reported to have asthma compared with $41 \%$ and $66 \%$ in the Southampton study ${ }^{16}$ and $34 \%$ in the Tyneside study. ${ }^{18}$ We did not consider the adequacy of the bronchodilator treatment or the use of prophylactic treatment.

We did not test bronchial responsiveness. Though this test would provide an objective measure for future comparison and previous population surveys have shown an association between clinical asthma and bronchial hyperresponsiveness, it lacks both sensitivity and specificity. In an Australian study $6.7 \%$ of those without symptoms of asthma had bronchial hyperresponsiveness and $66 \%$ of those with respiratory symptoms suggestive of asthma did not. ${ }^{19}$ This pattern was confirmed by a second Southampton study, in which $17 \cdot 5 \%$ of those without respiratory symptoms had bronchial hyperresponsiveness and $47 \%$ of those with a current history of wheeze and shortness of breath did not. ${ }^{20}$

Within its limitations our survey has identified a large increase in the prevalence of a history of wheeze or asthma in 7 year old children in Melbourne over the past 26 years and a high prevalence of current respiratory symptoms suggestive of asthma.

This study was funded by the Victorian Health Promotion Foundation in association with the Asthma Foundation of Victoria. We thank the research assistants Joanna Caust and Marita Dalton for achieving the high response rate and
Malcolm Rosier, Australian Council for Educational Research, for help with sample design.

1 Burr ML, Butland BK, King S, Vaughan-Wiliams E. Changes in asthma prevalence: two survevs 15 vears apart. Arch Dis Child 1989;64:1452-6.

Mitchell EA. Increasing prevalence of asthma in children. $N Z$ Z Med 1983:96:463-4.

3 Anderson HR. Increase in hospital admissions for childhood asthma: trends in referral, severity and readmissions from 1970 to 1985 in a heatlh region of the United Kingdom. Thorax 1989;44:614-9.

4 Mitchell EA, Anderson HR, Freeling P, White PT. Why are hospital admission and mortality rates for childhood asthma higher in New Zealand than in the United Kingdom? Thorax 1990;45:176-82.

5 Halfon N, Newacheck PW. Trends in the hospitalisation for acute childhood asthma. A m f Public Health 1986:76:1308-11.

6 Bauman A, Lyle D, Taylor L, Thomson P. The use of medical records in epidemiology: a case study using asthma hospitalisations in New South Wales, 1979-86. Australian Medical Records fournal 1990;20:105-5.

7 Burney PJ. Chinn S, Rona RJ. Has the prevalence of asthma increased in children? Evidence from the national study of health and growth 1973-86. R.117 1990;300:1306-10

8 Jackson RT, Sears MR, Beagleholc R, Rea HH. International trends in asthma mortalit, 1970-1985. Chest 1988:94:914-9.

9 Williams H, McNicol KN. Prevalence, natural history, and relationship of wheesy bronchitis and asthma in children. An epidemiological study. BMY 1969:iv:321-5.

10 Kish L. Survey sumpling. New York: Wiley and Sons, 1965

1 Burney PGJ, Chinn S. Developing a new questionnaire for measuring the prevalence and distribution of asthma. Chest 1987;91 suppl):79-83S.

12 Anderson HR, Bailey PR, Cooper JS, Palmer JC, West S. Morbidity and school absence caused by asthma and wheezy illness. Arch Dis Child 1983;58:777-84.

13 Asher MI, Pattemore PK, Harrison AC, et al. International comparison of the prevalence of bronchial hyperresponsiveness and asthma symptoms. Am Rev Respir Dis 1988;138:524-9.

It Keating G, Mitchell EA, Jackson R, Beaglehole R, Rea HH. Trends in sales of drugs for asthma in New Zealand, Australia, and the United Kingdom, 1975-81. B.117 1984;289:348-51.

15 Hurry VM, Peat JK, Woolcock AJ. Prevalence of respiratory symptoms, bronchial hyperresponsiveness and atopy in schoolchildren living in the Villawood area of Srdney, A ust N Z J Med 1988:18:745-52.

16 Clifford RD, Radford $M$, Howell JB, Holgate ST. Prevalence of respiratory symptoms among 7 and 11 year old scheolchildren and association with asthma. Arch Dis Child 1989;64:1118-25.

17 Jones DT, Sears MR, Holdaway MD, et al. Childhood asthma in New Zealand. Br 7 Dis Chest 1987;81:332-40.

18 Speight ANP, Lee DA, Hey EN. Underdiagnosis and treatment of asthma in childhood. BMF 1983;286:1253-6.

19 Salome CM, Peat JK, Britton WJ, Woolcock AJ. Bronchial hyperresponsiveness in two populations of Australian schoolchildren. 1. Relation to respiratory symptoms and diagnosed asthma. Clinics in Allergy 1987:17: $271-81$

20 Clifford RD, Howell JB, Radford M, Holgate ST. Associations between respiratory symptoms, bronchial response to methacholine and atopy in two age groups of schoolchildren. Arch Dis Child 1989:64:1133-9.

ticepted 12 March 1991

\section{Appendix}

RESPIRATORY SYMPTOMS QUESTIONNAIRE

1 Has you child ever had wheezing or whistling in the chest? 2 Has your child ever had asthma?

If yes to questions 1 or 2 then:

3 In the past 12 months has your child had a wheezing or asthma attack?

4 In the past 12 months how many wheezing attacks did your child have: (a) $<4$, (b) $4-12$, (c) $>12$ ?

5 In the past 12 months has any wheezing attack woken your child at night?

6 In the past 12 months has any wheezing attack been severe enough to limit speech to only one or two words at a time?

Everyone to answer the following questions:

7 In the past 12 months has your child sounded wheezy during or after exercise?

8 In the past 12 months has your child had a dry cough at night (apart from a cough associated with a cold or chest infection)?

9 In the past 12 months has your child usually brought up phlegm or mucous from the chest first thing in the morning? 10 In the past 12 months has your child woken with a feeling tightness in the chest first thing in the morning?

11 In the past 12 months has your child had tightness in the chest or become short of breath when near animals, feathers, or dust?

12 In the past 12 months has your child been treated at any time with any of the following drugs: Ventolin, Bricanyl, Nuelin, Somophyllin, Respolin, Berotec, Theo-Dur, Elixophyllin, or Slo-Bid?

13 Has your child ever had bronchitis?

14 Has your child ever suffered from wheezing with bronchitis or with a cold? 